for lay readers. Dr. Tarski rightly thinks otherwise. After a restricted account of the leading doctrines of symbolic logic (pp. 1-97), he gives a short exposition of the idea of number, of the simple arithmetical operations, followed by a short discussion of the methodology and the axiom-system of arithmetic. This is an illuminating and sufficient introduction to the analysis of the logical foundations of elementary arithmetic. But once the purpose and technique of the method are thoroughly understood, it will be easier for the reader to tackle the more advanced works on the subject. Dr. Tarski helps him in this connexion by suggesting a number of easy examples after each chapter. Controversial questions are carefully avoided, and the technical apparatus is reduced to a minimum, though one may have wished for practice' sake more symbolic formulæ and proofs. Yet, as it is, Dr. Tarski's book, with the authority of its author, who is a leading member of the Polish school of mathematical logicians, fulfils a real want and is well worthy of an English translation. T. G.

Explanation and Reality in the Philosophy of Emile Meyerson

By Prof. Thomas R. Kelly. Pp. xii + 134. (Princeton, N.J. : Princeton University Press ; London : Oxford University Press, 1937.) 9s. net.

$7 \mathrm{HE}$ epistemological doctrines of Meyerson have gained a permanent place in contemporary philosophy. The influence of this eminent thinker radiates beyond the wide circle of his disciples, and explains the importance of authoritative expositions of his doctrines, such as the one written by Prof. Kelly. The dramatic conflict between the way followed by explanation and the way followed by reality is the source of Meyerson's system. If he began by stressing these differences, however, Meyerson was led, later, to submit that some kind of convergence and identity of structure is necessary in order that the intent of knowledge may be achieved. Prof. Kelly follows closely the development of these doctrines, and while taking a sympathetic view of them, he does not fail to point out their outstanding deficiencies. This work can serve as an introduction not only to the philosophy of Meyerson, but also to the central problems to scientific thought.

\section{Examination of McTaggart's Philosophy}

By Prof. C. D. Broad. Vol. 2, Part 1. Pp. $1 x x v+514$. Vol. 2, Part 2. Pp. 515-796. (Cambridge: At the University Press, 1938.) 45s. net.

WITH the publication of these two parts of his "Examination", the detailed exposition and criticism of "The Nature of Existence" is brought to its completion with that touch of brilliant scholarship which characterizes the works of Prof. Broad. The profound meaning of McTaggart's philosophy is thus brought to light in a much larger work : it could scarcely be otherwise, if a thorough discussion of all the details of that great system was contemplated. In comparing "The Nature of Existence" with the "Examination", one cannot help feeling as much admiration for the analytical and critical effort of the second as for the powerful synthetic composition of the first. Here we can feel two minds grappling together with the major problems of thought and existence which have been the concern of the great thinkers of all times. It is then a kind of anti-climax to see Prof. Broad write at the end of his inquiry, that he was struck by the "thinness" of McTaggart's philosophy ; and that he asked himself whether all this speculative effort was worth doing at all. But perhaps it is in the very imperfection of all human attempts to solve the riddle of existence and yet in their ineluctable urge of trying to do so, that the eminent critic as well as any modest reader may find a cause for wonder at the achievements of the human intellect.

\section{Physics}

Electricity and Magnetism for Degree Students By Sydney G. Starling. Sixth edition. Pp. vii +630 . (London, New York and Toronto : Longmans, Green and Co., Ltd., 1937). 12s. 6d. net.

7 HIS well-known text-book has been extensively revised, and reset in larger type. The changes which have been made include the insertion of an account of the Hall and allied effects, and the omission of the description of the magnetization of ships. The sections on atomic phenomena have been extended considerably, and now provide a good introduction to this relatively new work. The book, which covers rather more than is needed for a pass degree in physics and provides a sound framework for an honours course, remains probably the best treatise of its kind in English on experimental electricity.

\section{Collisions of the Second Kind:}

Their Role in Physics and Chemistry. By Dr. E. J. B. Willey. Pp. viii $+150+1$ plate. (London: Edward Arnold and Co., 1937.) 10s. 6d. net.

7 HE molecular collisions most familiar to classical kinetic theory are those wherein the kinetic energy is conserved. The early successes of the dynamical theory of gases are due to the fact that certain atoms and simple molecules do, in fact, resemble elastic spheres under a variety of conditions. Latterly, however, an important group of phenomena has been discovered experimentally which shows that many gaseous collisions-particularly those involving electrons-occur with changes in the kinetic energy. The conditions which govern the conversion of kinetic energy into the various possible kinds of internal energy are as yet but dimly understood; and on that account alone, Dr. E. J. B. Willey's book is to be welcomed.

The subjects covered are diverse, and include the excitation of spectra, inelastic collisions at interfaces, resonance radiation and chemical reactions.

The book is the work of an enthusiast, who has himself contributed to the development of the subject. Prof. Frank is given fitting prominence throughout, and his portrait is included. We feel certain that Dr. Willey's work will be found helpful by a large number of research workers, to whom primarily it is addressed. E. A. Moelwyn-Hughes. 